\title{
A IMPORTÂNCIA DAS CORES NO DESENVOLVIMENTO E APLICAÇÃO NAS IDENTIDADES VISUAIS PRESENTES NO MERCADO - UMA REVISÃO.
}

THE IMPORTANCE OF COLORS IN THE DEVELOPMENT AND APPLICATION IN VISUAL IDENTITIES PRESENT ON THE MARKET - A REVIEW

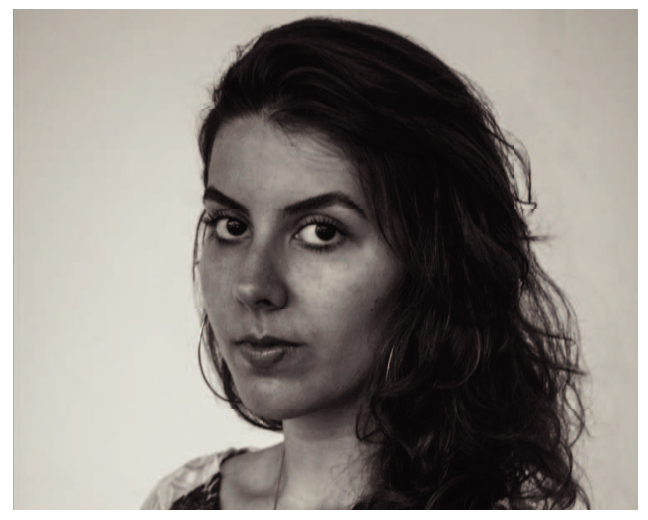

\section{Ana Laura Alves}

Graduanda em Design com Habilitação em Design de Produto pela Universidade Estadual Paulista Júlio de Mesquita Filho nalaudesign@gmail.com alves.analaura@faac.unesp.br

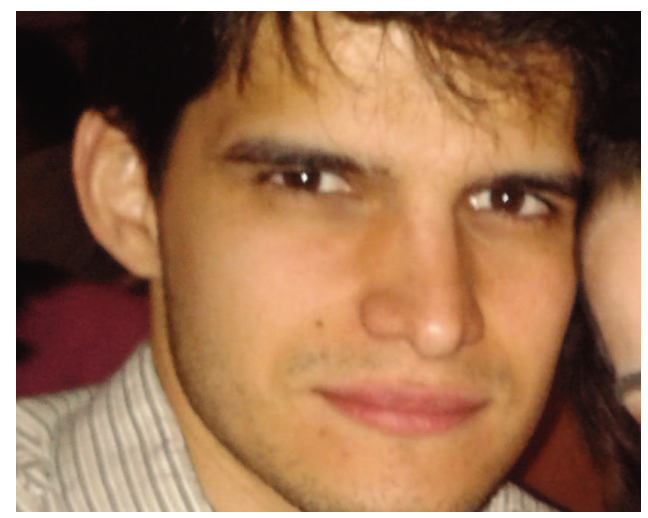

\section{João Carlos Riccó Plácido da Silva}

Doutorando em Desenho Industrial pela

Universidade Estadual Paulista Júlio de Mesquita

Filho, UNESP

Programa de Pós-Graduação em Design

joaocarlos_placido@hotmail.com

joaocplacido@gmail.com

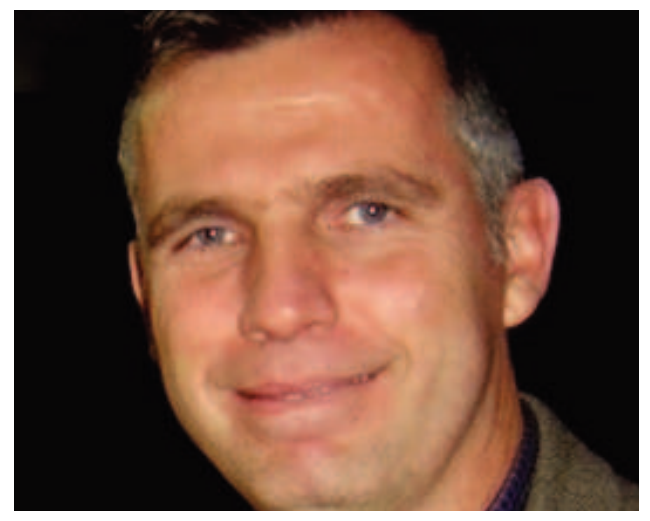

\section{Luis Carlos Paschoarelli}

Pós-doutorado em Ergonomia pela Universidade Técnica de Lisboa

Livre-Docente em Design Ergonômico pela Universidade Estadual Paulista paschoarelli@faac.unesp.br Icpascho@gmail.com 


\section{RESUMO}

O presente artigo pretende discutir a importância do estudo das cores, num processo anterior a sua aplicação no projeto gráfico de uma marca. Frequentemente empresas disputam o campo visual se utilizando das cores como um instrumento de diferenciação em relação ao apresentado pelos concorrentes, impondo aos usuários uma maior dificuldade na identificação e correlação entre a marca e sua respectiva empresa. Na maioria das situações a propaganda não representa as informações que pretende transmitir. $O$ estudo do impacto das cores é de extrema importância para o desenvolvimento de marcas, uma vez que é um dos componentes mais relevantes na identificação das marcas. Assim, considera-se que o design gráfico deve preconizar a ligação do uso das cores ao método de desenvolvimento de uma marca e sua associação à psicologia.

\section{PALAVRAS-CHAVE \\ Cores. Marca. Design.}

\section{ABSTRACT}

This article discusses the importance of studying the colors in an earlier case its application in the graphic project of a brand. Often companies dispute the visual field using color as an instrument of differentiation in relation to what the competitors present, giving users a greater difficulty in identifying and correlating a brand with its respective company. In most situations, advertisement does not represent the information companies want to convey. The study of the impact of colors is extremely important to develop brands, since color is one of the most relevant components of brand identification. Therefore, graphic design should advocate linking the use of color to the method of developing a brand and its association with psychology.

\section{KEYWORDS}

Color. Brands. Design.

\section{INTRODUÇÃO}

Diariamente o ser humano tem acesso a uma grande quantidade de informações, que são disponibilizadas nos mais variados meios de divulgação; como por exemplo, as notícias, as propagandas, os áudios, os vídeos, os materiais impressos, as mídias digitais, a internet, entre tantos outros. Esse volume exacerbado de informações pode gerar uma influência negativa sobre as empresas que as utilizam para veicular seus produtos. $\mathrm{Na}$ busca de visualização, esses são geralmente apresentados fortemente "carregados" ou apresentam cores para chamar a atenção dos usuários.

Desde a origem do homem a comunicação ocorre, predominantemente, por meio de símbolos e cores. Atualmente, tais símbolos são utilizados para identificar uma instituição, um produto, uma ideia ou um conceito, o que caracteriza a identidade visual, ou o conjunto de elementos formais, que representa visualmente e de forma sistematizada o nome, produto, a empresa, instituição ou o serviço. Portanto, o conjunto desses elementos tem como base o símbolo visual e seu conjunto de cores.

O designer gráfico tem como desafio criar e desenvolver uma identidade visual, a qual deve transmitir as ideias e intenções; e especificar o mercado que a mesma pretende agir. Para o desenvolvimento de um projeto de marca que possibilite a sua fácil compreensão deve-se considerar o provável repertório e valores dos usuários, os quais são amplos e desconhecidos. Especificamente, no caso das cores, isto se amplifica, pois muitos fatores e variáveis envolvem o seu significado e sua comunicação.

É crescente o número de instituições que buscam ampliar seus mercados, e para tal empregam cores e formas de maneiras arbitrárias e equivocada em 
suas marcas, o que pode levar a sobrecarga informacional. Portanto, pode-se afirmar que tais equívocos são decorrentes da negligência no trato de algumas informações relativas à marca, e, de igual importância, à forma que essas devem ser apresentadas aos usuários.

O presente artigo pretende discutir a importância do estudo das cores num processo anterior a sua aplicação no projeto gráfico de uma marca. Vale ressaltar que os indicadores baseados na percepção e na psicologia das cores são de grande importância para os designers, uma vez que facilitam a compreensão de uma marca, além do entendimento da influência que elas exercem sobre os usuários finais.

\section{MARCAS}

A marca pode ser considerada como a representação simbólica de uma instituição ou produto, algo que pode ser identificado de imediato, como um símbolo, um ícone ou uma palavra. Consiste em um signo sensível, isto é, uma junção da informação verbal com a informação visual; um signo linguístico utilizado para designar, verbalizar, escrever e interiorizar uma instituição, de maneira que esta se torne próxima e de fácil identificação pelo usuário (COSTA, 2008).

A concorrência gerada entre uma infinidade de empresas do mesmo ramo de atividade cria a necessidade de buscar-se uma ligação emocional entre as empresas e os seus clientes, na procura de um relacionamento duradouro e insubstituível, almejando a fidelização. Uma marca, quando consolidada, destacase num mercado saturado de produtos ou serviços similares. De modo geral, a literatura da área considera que as pessoas se apaixonam pelas marcas, confiam e acreditam na superioridade que transmitem. $O$ modo como as marcas são percebidas impacta diretamente na sua fixação, ou não fixação (WHELLER, 2009).

De modo efetivo, uma marca refere-se a uma representação gráfica no âmbito e competência do designer gráfico, o qual trabalha com a composição gráfica de um símbolo ou logotipo, tanto individualmente, como em conjunto (PEÓN, 2008).

Já um símbolo é um elemento gráfico que com o uso passa a identificar um nome, uma ideia, um produto ou um serviço. Strunck (2001), classifica os símbolos em dois grandes grupos: (1) abstratos e (2) figurativos. Símbolos abstratos, nada representam à primeira vista e seus significados devem ser apreendidos. Por outro lado, os símbolos figurativos podem ser de duas naturezas: (a) baseados em ícones, sendo assim fieis ao que pretendem representar, e (b) os ideogramas ou desenhos, os quais representam ideias/conceitos.

Nem toda marca necessita de um símbolo, uma vez que seu conceito pode ser representado totalmente pelo próprio código tipográfico. O exemplo apresentado a seguir (Figura 1) refere-se a uma loja de venda de embalagens, em que a ideia de embalar os produtos foi usada para a sua identificação. Nesse sentido, associouse uma moldura ao nome fantasia da empresa, apresentando a marca de modo simples, objetivo e de fácil compreensão e entendimento. Há ainda o auxílio da palavra "embalagem", a qual associa diretamente os produtos com os quais a empresa trabalha; uma vez que o nome fantasia "MULT" não se refere à linha de produtos, mas, sim à ideia de diversidade de produtos ofertados (SILVA, 2015).

O conceito de marca é bem mais abrangente que a simples representação de uma empresa através de seu nome fantasia e de sua representação gráfica. As marcas buscam comunicar os seus serviços e apontar suas diferenças e qualidades em relação aos seus concorrentes. Normalmente, busca-se associar a marca a uma personalidade ou imagem presente na mente do consumidor, de forma que a imagem seja associada à qualidade daquele serviço ou produto. Portanto, uma marca torna-se um dos elementos mais importantes para a publicidade de uma instituição, transformando-se na sua face: a primeira impressão causada no consumidor (SILVA, 2015). 
Figura 01- Logotipo da empresa Mult Embalagens.

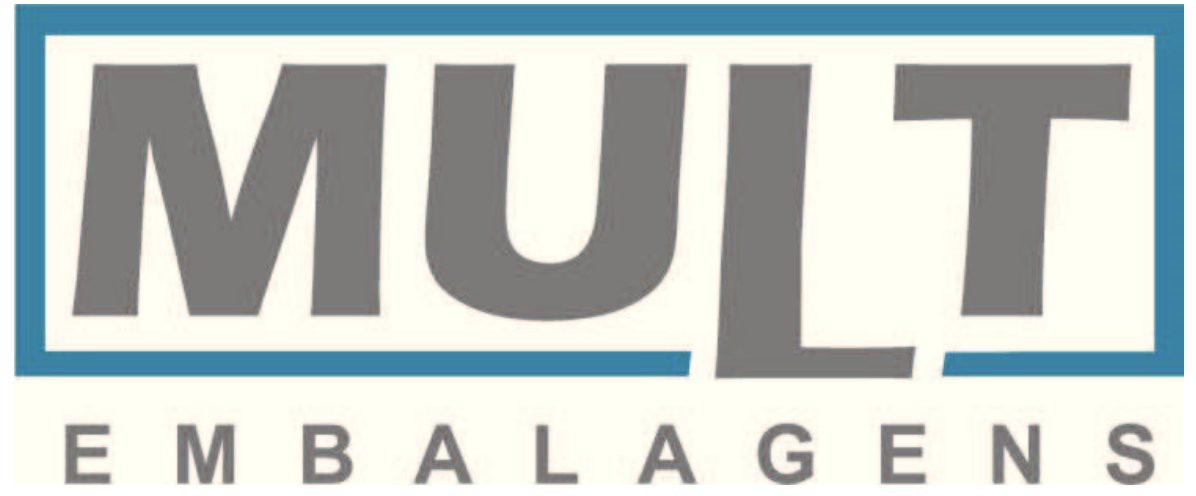

Fonte: Silva, 2015

\section{CORES}

O ser humano, em sua rotina diária, recebe informações através dos órgãos do sentido; sendo que a visão é responsável por captar cerca de $80 \%$ de tais mensagens, dentre as quais, $40 \%$ estão vinculadas exclusivamente à cor. $O$ sentido da visão recebe e armazena um número infinito de unidades de informação em uma fração de segundo. Os mecanismos fisiológicos acontecem de forma automática no sistema nervoso, que identifica as necessidades, as preferências, os prazeres com base no que vê ou no que quer ver. A cor, neste contexto, é a informação do meio que mais rapidamente é captada pelo indivíduo quando comparada à forma do objeto (DONDIS, 2007; EYSENCKEY, 2007).

O aparecimento da cor está condicionado à existência de dois elementos: a luz e o olho. A primeira é o objeto físico que age como estímulo e o segundo é o órgão receptor que funciona como decifrador do fluxo luminoso. Dessa forma, pode-se afirmar que a cor não é uma propriedade particular dos objetos, mas um atributo perceptual que permite a identificação e localização de padrões ambientais de mesmo brilho (GUIMARÃES, 2000). A absorção de luz pelas células receptoras, presentes na retina, é o primeiro passo que leva à percepção visual. Existem dois tipos de células fotorreceptoras: (1) os bastonetes, responsáveis pela visão noturna, com pouca participação na visão de cores e; (2) os cones, ativados por luz, responsáveis pela visão diurna, fundamentais na visão de cores (XIAO, 2000; VENTURA, 2007).

A cor está relacionada com ondas de espectros eletromagnéticos diferentes e é somente percebida em uma faixa específica, considerada zona visível. O objeto só tem cor se absorver os raios correspondentes a uma frequência determinada (Figura 2). Por exemplo, um objeto é vermelho se ele absorver todas as outras ondas e refletir a onda de cor vermelha (AMBER, 1983). Considerando a cor como luz, o branco é o resultado da sobreposição de todas as cores primárias, ou seja, o azul, o verde e o vermelho; enquanto o preto é a ausência da luz. O primeiro a conseguir decompor o espectro luminoso em um prisma foi Issac Newton, no século XVII. Na natureza, essa decomposição de cores pode ser observada no arco-íris (lbid.). 
Figura 2- Espectro Visível adaptado pelo autor

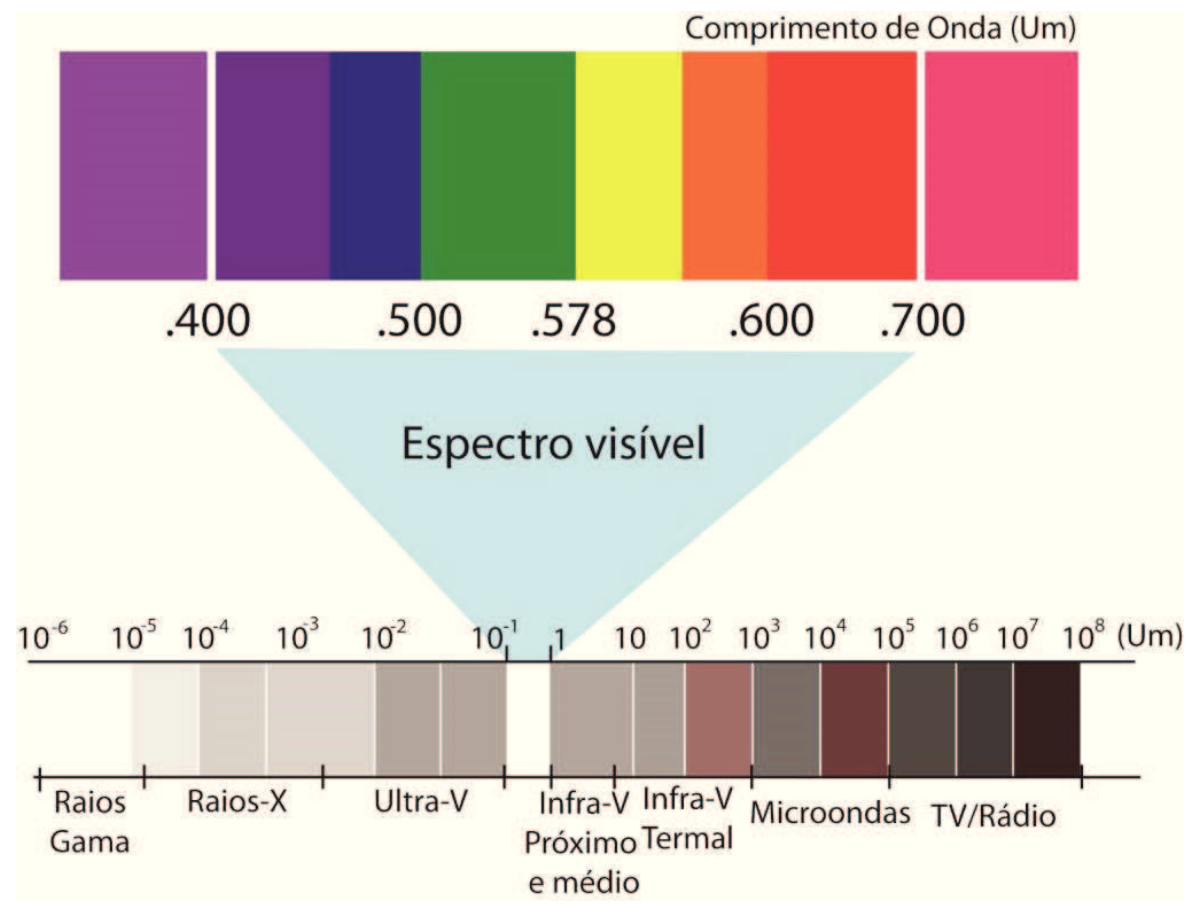

Fonte: adaptado pelos autores de Amber (1983).

\subsection{PERCEPÇÃO DA COR}

A percepção da cor não se restringe apenas aos olhos (retina), mas também associa-se às informações que estão presentes no cérebro. Por exemplo, se um objeto da cor laranja estiver pobremente iluminado, este poderá ser visto por alguns como sendo amarelado ou avermelhado. Neste sentido, a cor pode ser considerada uma representação interna em nível cerebral, ou seja, os objetos em si não têm cor, uma vez que essa corresponde a uma sensação interna provocada por estímulos físicos da natureza que dão origem à percepção da mesma cor por um ser humano (PEDROSA, 2009).

Outro exemplo da autorregulação do cérebro, em relação à percepção da cor no ambiente, é o uso de óculos com lentes coloridas. Um óculos com uma lente verde e a outra vermelha, retirado após um período de uso, causará a sensação, durante um determinado tempo, de que tudo parecerá esverdeado quando se olha para um lado, ou avermelhado, quando se olha para o outro. Neste sentido, o cérebro tem a capacidade de corrigir a cor que "tinge" os objetos, fazendo com que pareçam ter a cor presente na memória visual recente (AMBROSE e HARRIS, 2009). Este tipo de percepção, também denominado de constância da cor, é o que faz com que a maioria das cores das superfícies demonstra ter aproximadamente a sua aparência, mesmo quando está sendo vista sob uma iluminação muito diferente (Ibid.). Mesmo que a iluminação mude, a mente humana reconhece certos padrões constantes nos estímulos perceptivos, de maneira que agrupa e classifica fenômenos diferentes como se fossem iguais. $O$ que se enxerga não é exatamente o que está representado, na verdade corresponde a um modelo simplificado da realidade que é importante para a sobrevivência (lbid.).

Os estímulos físicos não agem diretamente nos organismos complexos, mas sim na informação sobre a representação interna dos padrões de atividade neural. Os estímulos fornecem informação sobre o que é apenas a qualidade sensorial, que se denomina cor, a qual surge nos mecanismos sensoriais decorrentes do processo de aprendizagem e é, por este motivo, projetada sobre os estímulos. Com uma grande variedade de combinações de estímulos diferentes, pode-se 
gerar os mesmos padrões de atividade neural correspondentes ao mesmo atributo de qualidade sensorial. Por isso, os seres detectem a presença de comida ou de predadores, em qualquer ambiente e iluminação. Esse é um modelo simplificado do mundo que permite uma avaliação rápida de situações complexas e que se mostra útil e adequado à manutenção de uma espécie (BANKS, 2007).

O sistema sensorial dos seres humanos faz emergir vários tipos de cores com diferenças de tonalidades que, no decorrer do tempo, foram categorizados, associando-se a determinados nomes e bandas de tonalidade. Um hábito comum do ser humano é o de categorizar, o que faz imaginar que o nosso sistema nervoso realiza uma seleção objetiva de uma determinada cor existente no mundo (SILVA, 2012)

\subsection{PSICOLOGIA DA COR}

Evidências científicas sugerem que a luz de diversas cores entra pelos olhos e afeta diretamente o centro das emoções. Cada ser humano responde à cor de uma forma particular. Algumas pessoas tendem a ser atraídas por certas cores em virtude de alguns fatores que determinam essa aproximação. A escolha pode estar vinculada à personalidade e às condições de vida ou de desejos e à processos mentais mais íntimos e profundos, provavelmente inconscientes (AMBROSE e HARRIS, 2009).

Diversos testes psicológicos desenvolvidos para possibilitar uma melhor compreensão do uso das cores pelo ser humano são relatados por Ambrose e Harris (2009). Por exemplo, uma atração forte de uma pessoa pela cor vermelho pode indicar uma personalidade afirmativa e extrovertida ou de alguém determinado. Todavia, a aversão a essa cor, sugere um individuo tímido e retraído, provavelmente isolado de sua comunidade. Nesse sentido, as cores podem representar uma influência das características físicas, cognitivas e emocionais dos indivíduos (ibid).

De acordo com Amber (1983), a cor pode ser utilizada para acalmar e relaxar as pessoas, o que é preconizado pela cromoterapia, que utiliza as cores na busca da cura de doenças. Desde civilizações remotas, como no Egito Antigo, na Índia, Grécia e China, as cores são usadas com o objetivo de harmonizar o corpo, atuando do nível físico e psíquico dos indivíduos e suas comunidades. Para Hipócrates, ter saúde ou doença dependia da harmonia entre o meio ambiente, o corpo e a mente. Desta forma, a cor pode ser empregada nesses três meios em benefício de uma vida melhor. Os adeptos dessa terapia compreendem que cada cor possui uma vibração específica e propriedade terapêutica (AMBER, 1983).

Johann Wolfgang Von Goethe, pesquisador alemão, no século XVIII, foi o primeiro a estudar esse tipo de terapia. Durante 40 anos pesquisou sobre as cores e observou que o vermelho tem propriedade estimulante no organismo, o azul acalma, o amarelo provoca sensação de alegria e o verde é repousante, e que, seus efeitos são mais ou menos intensos, dependendo da tonalidade utilizada (Ibid.).

A compreensão e as propriedades atribuídas à cor variam de acordo com a cultura de cada região onde o ser humano está inserido. Desta forma, na cultura ocidental uma determinada cor pode ter alguns significados, enquanto na cultura oriental, outros (BANKS, 2007). No ocidente, por exemplo, o uso de algumas cores, nas comemorações de passagem do ano, simbolizam sorte, esperança, amor, dinheiro. Em algumas regiões, a cor predominante neste período é o branco, que representa paz, ou ainda, o uso da cor verde indica esperança no próximo ano. (BANKS, 2007).

$\mathrm{Na}$ área de Design, compreender as cores e saber utilizá-las de maneira adequada possibilita a produção de projetos funcionais, propiciando a criação de produtos e sistemas informacionais que não só transmitem suas qualidades e funcionalidade através da forma, mas também através da cor, tanto em design gráfico como de produto. 


\section{A COR NA MARCA}

A cor, que pode se tornar mais importante que os próprios logotipos e/ou símbolos, tem atributos que podem remeter a aspectos da emoção e ao poder de fixação. Um exemplo é a cor vermelha da marca da Coca-Cola (Figura 3).

Figura 3 - Marca da Coca-Cola

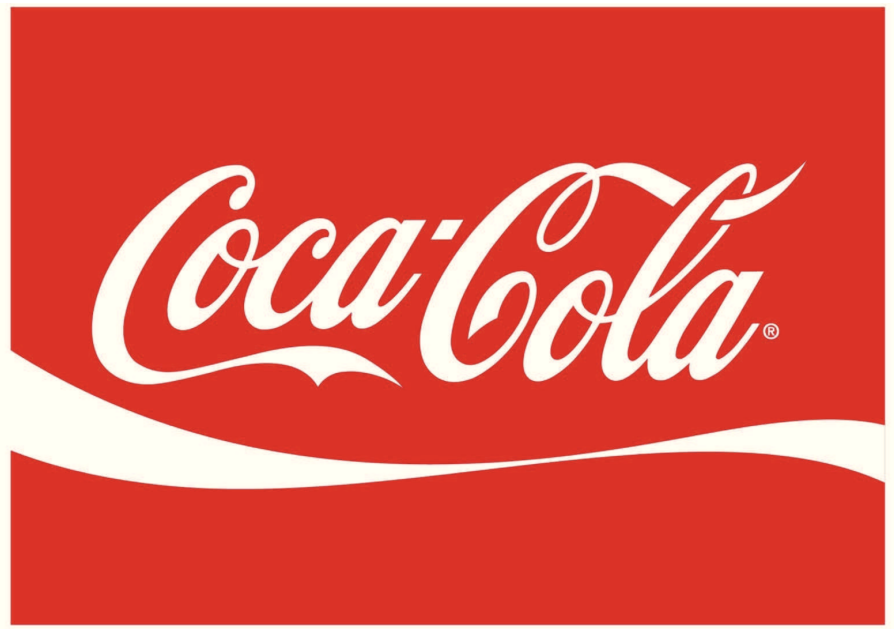

Fonte: Wheller, 2009

Diversas pesquisas demonstram que as cores se relacionam com a emoção de um modo mais direto e uniforme do que as formas. Portanto, em um projeto de identidade visual, deve-se dar uma grande importância e atenção às cores. Por outro lado, a manipulação cromática é extremamente complexa, uma vez que seus diversos tons, luminosidade e saturação permitem uma gama infinita de combinações. Além disso, é importante verificar se a cor será aceita para a categoria a qual está sendo destinada (SILVA, 2012).

De acordo com Bonnici (2000), a linguagem visual comunica-se através de mensagens diversas, sendo que os elementos que a compõem relacionam-se entre si: imagens, cores, formas, aspecto gráfico, proporção, tons e texturas. A mensagem visual codifica-se, normalmente, em uma imagem que às vezes apoiase em aparatos verbais; como na identidade visual, em que o nome da instituição é associado com uma imagem que transmite suas qualidades ao sujeito (BONNICl, 2000).

Aspectos relacionados ao uso da cor têm apresentado mudanças nos últimos anos, em grande parte nos projetos de identidade visual. O emprego de poucas cores, por exemplo, era normalmente indicado para diminuir custos, já que quanto mais cores empregadas em um projeto, maior o investimento financeiro na sua implantação. Atualmente, o uso de poucas cores tem outra conotação: a vantagem de facilitar a fixação da marca pelo usuário. As cores escolhidas para determinadas marcas devem ser testadas, analisadas se estão sempre sendo percebidas (mesmo quando do emprego do preto e do branco, uma vez que nem sempre estas são consideradas cores), sem que haja o comprometimento da leitura. Além disso, o projeto deve ser impresso geralmente em uma única cor quando tiver aplicação destinada às diferentes mídias impressas, tornando-se assim mais acessível (SILVA, 2012).

O estudo de cores faz parte da etapa criativa do método de desenvolvimento de um projeto, quando a forma e a tipografia em fase de definição associadas a este recurso de contraste e finalização da conceituação, enfatizam as qualidades que devem ser transmitidas ao usuário. Na definição da escala cromática, é indicada a utilização do mínimo de cores, com poucas variações, sobretudo para o caso 
de impressos, como mencionado anteriormente. Entretanto, para uma marca veiculada através dos meios digitais, é interessante a utilização de mais cores, com mais variações, com o intuito de despertar a atenção do público e torna-la mais funcional. Contudo, a utilização de muitas cores deve ser feita com base em critérios preestabelecidos (Ibid.).

Ao definir uma combinação cromática, seus tons obrigatoriamente devem se manter inalterados. Nessecaso, as informações da identidade não se desconfiguram no momento da sua aplicação na marca e na busca primordial de sua fixação. As cores apresentam, ainda, atributos que podem remeter aos aspectos da emoção e, principalmente, ao poder de fixação. Um exemplo a ser citado é o da cor utilizada na marca do Banco Itaú. Recentemente, uma propaganda veiculada na televisão aberta brasileira relativa à essa instituição utilizou exclusivamente o tom de laranja, sem mesmo ter apresentado, em qualquer momento, a marca Itaú. Este é um bom exemplo de que, em alguns casos, a cor se sobrepõe a própria marca (SILVA, 2012).

A cor ou combinação cromática consiste no terceiro componente do código de identidade visual - onde o primeiro é o símbolo e o segundo, a tipografia. Os três componentes devidamente organizados e combinados contribuem para a identificação da empresa. Assim, as cores precisam ser utilizadas adequadamente pelo designer para criar fortes fatores de expressão de identidade (PINHO, 1996).

\section{NOTAS CONCLUSIVAS}

A percepção da cor é inerente aos seres humanos e pode influenciar no seu cotidiano de maneira positiva ou negativa. $O$ uso das cores em roupas pode refletir o humor de quem a veste e representar um tipo de sensação. $O$ sistema sensorial detecta diversos tipos de cores e tonalidades que representam um universo de sensações e possibilidades. Estas podem ser transmitidas aos usuários por meio de produtos e sistemas informacionais e, no caso específico da discussão aqui apresentada, também estão presentes no desenvolvimento de marcas.

A marca representa uma empresa, uma instituição, uma família e suas características, ou seja, informações. O conceito vai além da representação gráfica, uma vez que traz um significado tanto gráfico como sensorial e se relaciona diretamente com a cor empregada e com a região na qual está inserida. Projetos de identidade de marca buscam associar a personalidade, a qualidade do serviço ou produto ao público alvo.

O primeiro contato estabelecido entre serviço ou produto é a visualização da marca, o que torna fundamental o correto emprego das cores, que em alguns casos assume mais importância que a própria forma. Mensagens são transmitidas através destas formas organizadas e dispostas para o usuário identificar-se ou tornar-se próximo ou simplesmente para que sejam vistas dentre tantas outras. Nos projetos, os elementos têm que compor e relacionar-se de maneira harmoniosa respeitando elementos como imagem, forma, aspecto gráfico, proporção, tons, texturas e cor.

A utilização dos conceitos de cor possibilita o estudo das informações que cada tonalidade transmite ao sistema psicológico do usuário. Compreender as características de cada cor é de extrema relevância e preocupação, uma vez que no ocidente e no oriente estas podem representar informações distintas, ter significados diferentes. Estudos aprofundados destes significados possibilitam uma maior abrangência da aplicação da marca não só em uma região, mas em todo o mundo. Portanto, a etapa do estudo cromático no projeto torna-se obrigatória e de grande importância para o seu sucesso.

\section{AGRADECIMENTOS}

Este estudo foi desenvolvido com o apoio da CAPES - Coordenação de Aperfeiçoamento de Pessoal de Nível Superior e CNPq - Conselho Nacional de Desenvolvimento Científico e Tecnológico. 


\section{REFERÊNCIAS}

AMBER, Reuben. Cromoterapia. Editora Pensamento-Cultrix Ltda, São Paulo, 1983.

AMBROSE, Gave; HARRIS, P. Cor. Porto Alegre/RS, Editora Bookman Companhia, 2010.

BANKS Adam. $O$ guia completo da cor. São Paulo/SP. Editora Senac, 2007.

BONNICl, Peter. Linguagem Visual. 0 misterioso meio de comunicação. Lisboa: Destartes, 2000.

COSTA, Joan. A Imagem da marca, um fenômeno social. São Paulo: Editora Rosari, 2008.

DONDIS, Donis A. Sintaxe da linguagem visual. São Paulo: Martins Fontes, 2007.

EYSENCKEY, Michael W.; KEANE, M. Manual de psicologia cognitiva. Porto Alegre: Artmed, 2007.

GUIMARÃES, Luciano. A Cor como Informação: A Construção Biofísica, Linguística e Cultural da Simbologia das Cores. São Paulo: Annablume, 2000.

PEDROSA Israel. Da cor a cor inexistente. SP, Senac, 2009

PEÓN, Maria Luisa. Sistemas de Identidade Visual. Rio de Janeiro: Editora 2AB, 2008.

SILVA, José Carlos Riccó Plácido da. et. al. The study of Informacional Ergonomy about symbols used in Graphic Marks. Las Vegas: Proceedings of AHFE, 2015.

SILVA, José Carlos Riccó Plácido da. Diretrizes para análise e desenvolvimento de identidade visual - contribuições para o design ergonômico. Dissertação (Mestrado em Design) - Universidade Estadual Paulista, Bauru, 2012.

STRUNCK Gilberto. Como Criar Identidades Visuais Para Marcas de Sucesso. Rio de Janeiro: Rio Books, 2001.

VENTURA, Dora Fix. Visão das cores no primeiro ano de vida. Psicologia USP, 18 (2). São Paulo, 2007.

XIAO, Ming.; HENDRICKSON, A. Spatial and temporal expression of short, long/medium, or both opsins in human fetal cones. Journal of Comparative Neurology, 425(4), 2000.

WHELLER, Alina. Design de Identidade da Marca. Porto Alegre: Editora Bookman, 2009.

\section{Ana Laura Alves}

Cursa graduação em Design com Habilitação em Design de Produto pela Universidade Estadual Paulista "Júlio de Mesquita Filho" (UNESP). Participou do Projeto de Extensão SOMA, sob orientação do Prof. Dr. Dorival Campos Rossi. Atualmente, é bolsista (PIBITI/CNPq) no Laboratório de Ergonomia e Interfaces, sob orientação do Prof. Dr. Luis Carlos Paschoarelli. Participa do Projeto Da Classe 
Ao Mercado, parceria entre a Universidade de Sevilha e a UNESP.

\section{João Carlos Riccó Plácido da Silva}

É doutorando do programa de pós graduação em Design da Universidade Estadual Paulista Júlio de Mesquita Filho. Possui mestrado em Desenho Industrial pela Universidade Estadual Paulista Júlio de Mesquita Filho (2012) e graduação em Desenho Industrial pela Universidade Estadual Paulista Júlio de Mesquita Filho (2009). Atualmente é professor da USC ( Universidade do Sagrado Coração) e de desenho - Sketch Arte. Tem experiência na área de Desenho Industrial, com ênfase em Programação Visual, atuando principalmente nos seguintes temas: design, programação visual, desenho industrial, comunicação visual, ergonomia informacional e tecnologia

\section{Luis Carlos Paschoarelli}

É Bolsista de Produtividade em Pesquisa do CNPq - Nível 1D - CA DI - Desenho Industrial, Livre-Docente em Design Ergonômico pela Universidade Estadual Paulista (2009); possui pós-doutorado em Ergonomia (2008) pela Universidade Técnica de Lisboa; doutorado em Engenharia de Produção (2003) pela UFSCar; Mestrado em Projeto, Arte e Sociedade - Desenho Industrial (1997) e graduação em Desenho Industrial (1994) pela UNESP. É co-lider no Grupo de Pesquisa Design Ergonômico: Projeto e Interfaces onde coordena os projetos de pesquisa: Design Ergonômico: avaliação e intervenção ergonômica no projeto, Design Ergonômico: metodologias para a avaliação de instrumentos manuais na interface homem $X$ tecnologia e Contribuições do Design Ergonômico na pesquisa e projeto de equipamentos para a reabilitação de pessoas com capacidades específicas. Está lotado no Laboratório de Ergonomia e Interfaces - Departamento de Design, onde atua como docente no curso de graduação em Design e do Programa de Pós-graduação em Design da UNESP. Tem experiência na área do design, ergonomia, design ergonômico, design de produto e design gráfico. Atualmente é o coordenador do Programa de Pós-graduação em Design - Mestrado e Doutorado - da UNESP e "Ergonomista Sênior" da ABERGO - Associação Brasileira de Ergonomia. 